\title{
Clinical Influence of the Lymph Node Ratio on Lymph Node Metastasis-positive Gastric Cancer Patients Who Receive Curative Treatment
}

\author{
TORU AOYAMA ${ }^{1,2^{*}}$, KESIKEU KOMORI $^{1,2^{*}}$, AYAKO TAMAGAWA $^{1}$, MASATO NAKAZANO $^{1,2}$, \\ KENTARO HARA $^{1,2}$, ITARU HASHIMOTO ${ }^{1}$, HIROSHI TAMAGAWA ${ }^{1}$, KENKI SEGAMI ${ }^{1}$, \\ YUKIO MAEZAWA $^{1,2}$, KAZUKI KANO $^{1}$, TAKASHI OSHIMA ${ }^{1,2}$, NORIO YUKAWA ${ }^{1}$ and YASUSHI RINO ${ }^{1}$ \\ ${ }^{1}$ Department of Surgery, Yokohama City University, Yokohama, Japan; \\ ${ }^{2}$ Department of Gastrointestinal Surgery, Kanagawa Cancer Center, Yokohama, Japan
}

\begin{abstract}
Background/Aim: The present study investigated the clinical impact of the lymph node ratio (LNR) on overall survival (OS) and recurrence-free survival (RFS) in cancer patients with lymph node metastasis who received curative treatment. Patients and Methods: Eighty-six patients who received curative surgery for gastric cancer between 2000 and 2015, and in whom lymph node metastasis was pathologically confirmed, were included in this study. The LNR was defined as the ratio of the number of metastatic lymph nodes to the total number of harvested lymph nodes. Results: A lymph node ratio of 0.23 was considered the optimal cutoff point for classification according to OS Statistically significant differences were observed in the 3and 5-year OS rates and 3- and 5-year RFS rates. The 3year and 5-year $O S$ rates in the LNR $<0.23$ group were $57.6 \%$ and $57.6 \%$, respectively, whereas those in the LNR $\geq 0.23$ group were $33.0 \%$ and $0 \%(p<0.001)$. The 3 -year and 5 -year RFS rates in the LNR $<0.23$ group were $45.9 \%$ and $43.6 \%$, respectively, whereas those in the $L N R>0.23$ group were $25.2 \%$ and $0 \%(p=0.002)$. Regarding the site of first relapse, the incidence rates of peritoneal and lymph node metastasis in the LNR >0.23 group were significantly different in comparison to the $L N R<0.23$ group. Conclusion: A high LNR was associated with significantly
\end{abstract}

This article is freely accessible online.

*These Authors contributed equally to this study.

Correspondence to: Toru Aoyama, Department of Surgery, Yokohama City University, 3-9 Fukuura, Kanazawa-ku, Yokohama 236-0004, Japan. Tel: +81 457872800, e-mail: t-aoyama@lilac.plala.or.jp

Key Words: Gastric cancer, lymph node metastasis-positive, lymph node ratio. worse OS and RFS in patients who received curative treatment for gastric cancer. The lymph node metastasis status should be utilized in the development of treatment strategies for gastric cancer.

Worldwide, gastric cancer is the third-most common cancer and the second leading cause of cancer-related death (1-3). Gastrectomy with D2 lymph node dissection is the standard procedure for locally advanced gastric cancer. Lymph node metastasis is among the most important prognostic factors for gastric cancer (4-6). In the TNM staging system of the Union for International Cancer Control (UICC), the $\mathrm{N}$ factor is determined according to the number of metastatic lymph nodes among harvested lymph nodes (7). For an accurate evaluation of the lymph nodes, the UICC and Japanese Gastric Cancer Association's 15th edition of the general rules for gastric cancer currently recommend the harvesting of $\geq 16$ lymph nodes (8). However, the number of metastatic lymph nodes depends on the number of the harvested lymph nodes. Thus, the number of the lymph nodes that are harvested may have an impact on the evaluation of the lymph nodes and an under and overestimation of stage. For the improvement of survival of patients with gastric cancer, the $\mathrm{N}$ factor should be considered.

Recently, the lymph node ratio (LNR) has attracted attention for its value in the evaluation of the $\mathrm{N}$ factor in some gastrointestinal malignancies, including gastric cancer (9-12). The LNR is defined as the number of metastatic lymph nodes to the number of harvested lymph nodes. However, the number of studies that have evaluated the clinical influence of LNR in gastric cancer is limited (1315). Furthermore, the optimal cutoff value for the LNR remains controversial. In the present study, we investigated whether the LNR influences overall survival (OS) and recurrence-free survival (RFS) of patients with lymph nodepositive gastric cancer. 
Table I. Comparison of survival rates stratified by patient characteristics.

\begin{tabular}{|c|c|c|c|c|c|}
\hline Characteristics & No. of patients $(\%)$ & 1 -year OS rate $(\%)$ & 3 -year OS rate $(\%)$ & 5 -year OS rate $(\%)$ & $p$-Value \\
\hline Gender & & & & & 0.554 \\
\hline Male & $56(65.1)$ & 87.4 & 48.3 & 44.6 & \\
\hline Female & $30(34.9)$ & 79.2 & 49.0 & 37.3 & \\
\hline Age (years) & & & & & 0.155 \\
\hline$<70$ & $41(47.7)$ & 85.4 & 53.7 & 53.7 & \\
\hline$\geq 70$ & $45(52.3)$ & 84.0 & 43.2 & 31.9 & \\
\hline Pathological type & & & & & 0.583 \\
\hline Intestinal & $44(51.1)$ & 81.8 & 48.2 & 41.5 & \\
\hline Diffuse & $42(48.9)$ & 87.6 & 48.5 & 41.6 & \\
\hline Pathological T status & & & & & 0.003 \\
\hline $\mathrm{T} 1$ to $\mathrm{T} 2$ & $23(26.7)$ & 95.5 & 75.9 & 75.9 & \\
\hline $\mathrm{T} 3$ to $\mathrm{T} 4$ & $63(73.3)$ & 80.8 & 39.0 & 30.1 & \\
\hline Lymph node ratio & & & & & $<0.001$ \\
\hline$<0.23$ & $54(62.8)$ & 92.5 & 57.6 & 57.6 & \\
\hline$\geq 0.23$ & $32(31.2)$ & 71.4 & 33.0 & 0.0 & \\
\hline Lymphatic invasion & & & & & 0.684 \\
\hline Negative & $10(11.6)$ & 90.0 & 50.0 & 50.0 & \\
\hline Positive & $76(84.4)$ & 84.0 & 48.5 & 41.6 & \\
\hline Vascular invasion & & & & & 0.934 \\
\hline Negative & $17(19.8)$ & 88.2 & 44.6 & 44.6 & \\
\hline Positive & $69(80.2)$ & 83.8 & 49.7 & 41.6 & \\
\hline Postoperative surgical complications & & & & & 0.149 \\
\hline No & $48(55.8)$ & 89.2 & 55.8 & 50.7 & \\
\hline Yes & $38(44.2)$ & 78.9 & 40.6 & 32.8 & \\
\hline
\end{tabular}

OS: Overall survival.

\section{Patients and Methods}

Patients. This retrospective study targeted 288 gastric cancer patients who received curative gastrectomy with lymphadenectomy at Yokohama City University between 2000 and 2015. Eighty-six patients who met the following inclusion criteria were included in the study: 1) histologically proven gastric adenocarcinoma with lymph node metastasis, 2) R0 curative gastrectomy, and 3) $\geq 16$ harvested lymph nodes. Patients who received preoperative chemotherapy and/or radiation therapy were excluded from the present study.

Surgical procedure and adjuvant treatment. Patients with gastric cancer undergo distal or total gastrectomy with radical lymphadenectomy. In principle, the extent of dissection is determined according to the third edition of the Japanese Gastric Cancer Association's Gastric Cancer Treatment Guidelines (16). Spleen-preserving D2 total gastrectomy was permitted in this study. After surgery, patients with pathological II or III disease received adjuvant chemotherapy for one year. In principle, S-1 monotherapy was administered to patients with pathological stage II disease, and S-1 plus docetaxel or capecitabine+oxaliplatin therapy was administered to patients with pathological stage III disease (17-19).

Harvesting of lymph nodes. During surgery, the stomach and perigastric tissues containing the lymph nodes, fat, and vessels were removed in a single block (so-called en-bloc dissection). The perigastric tissues were then separated from the stomach and divided into the following three areas: 1) the area containing the lymph nodes located along the proper hepatic, common hepatic, celiac, and splenic arteries, 2) the area that was previously attached to the lesser curvature, which contained the lymph nodes along the right and left gastric arteries, and 3) the area that was attached to the greater curvature and which contained the lymph nodes along the right and left gastro-epiploic arteries. Lymph nodes were harvested from each area immediately after surgery. First, all palpable lymph nodes were removed from each area. Usually, most lymph nodes could be harvested from the area along the major branched arteries using this method because the amount of fat tissue in this area was limited. In contrast, the lymph nodes in the lesser and greater curvatures were buried in fatty tissue. Subsequently, the remaining tissues were sliced and stretched for the detection of visible lymph nodes. Thereafter, we fixed the resected stomach and all harvested lymph nodes with $10 \%$ buffered formalin for at least $48 \mathrm{~h}(20)$.

Follow-up. Hematological tests and physical examinations were performed at least every three months for 5 years after surgery. Carcinoembryonic antigen and CA19-9 tumor marker levels were evaluated at least every 3 months for 5 years. Computed tomography (CT) scans were performed every 6-12 months for 5 years.

Evaluations and statistical analyses. The chi-squared test was used to compare differences between the LNR and clinicopathological parameters. OS and RFS were defined as the period between the date of surgery and death and the period between surgery and the occurrence of an event, recurrence, or death, whichever came first, respectively. OS and RFS curves were drawn using the Kaplan- 
Table II. Uni- and Multivariate Cox proportional hazards analysis of clinicopathological factors for overall survival.

\begin{tabular}{|c|c|c|c|c|c|c|c|}
\hline \multirow[b]{2}{*}{ Factors } & \multirow[b]{2}{*}{ No } & \multicolumn{3}{|c|}{ Univariate analysis } & \multicolumn{3}{|c|}{ Multivariate analysis } \\
\hline & & OR & $95 \% \mathrm{CI}$ & $p$-Value & OR & $95 \% \mathrm{CI}$ & $p$-Value \\
\hline Age (years) & & & & 0.159 & & & \\
\hline$<70$ & 41 & 1.000 & & & & & \\
\hline$\geq 70$ & 45 & 1.542 & $0.845-2.814$ & & & & \\
\hline Gender & & & & 0.555 & & & \\
\hline Woman & 30 & 1.000 & & & & & \\
\hline Man & 56 & 1.203 & $0.650-2.227$ & & & & \\
\hline Pathological type & & & & 0.584 & & & \\
\hline Intestinal & 44 & 1.000 & & & & & \\
\hline Diffuse & 42 & 1.181 & $0.651-2.140$ & & & & \\
\hline $\mathrm{T}$ status & & & & 0.006 & & & 0.044 \\
\hline $\mathrm{T} 1$ to $\mathrm{T} 2$ & 23 & 1.000 & & & 1.000 & & \\
\hline $\mathrm{T} 3$ to $\mathrm{T} 4$ & 63 & 3.698 & $1.454-9.405$ & & 2.733 & $1.029-7.262$ & \\
\hline Lymph node ratio & & & & $<0.001$ & & & 0.016 \\
\hline$<0.23$ & 54 & 1.000 & & & 1.000 & & \\
\hline$\geq 0.23$ & 32 & 2.849 & $1.559-5.207$ & & 2.172 & $1.157-4.077$ & \\
\hline Lymphatic invasion & & & & 0.684 & & & \\
\hline Negative & 10 & 1.000 & & & & & \\
\hline Positive & 76 & 1.213 & $0.477-3.086$ & & & & \\
\hline Vascular invasion & & & & 0.934 & & & \\
\hline Negative & 17 & 1.000 & & & & & \\
\hline Positive & 69 & 1.032 & $0.496-2.147$ & & & & \\
\hline Postoperative complications & & & & 0.153 & & & \\
\hline No & 48 & 1.000 & & & & & \\
\hline Yes & 38 & 1.542 & $0.852-2.793$ & & & & \\
\hline
\end{tabular}

Meier method. Univariate and multivariate survival analyses were performed using a Cox proportional hazards model. $p$-Values of $£ 0.05$ were considered to indicate statistical significance. All statistical analyses were performed using SPSS (v27.0 J Win; SPSS, Chicago, IL, USA). The present study was approved by the IRB of Yokohama City University.

\section{Results}

Patients. A total of 86 patients were evaluated. The median number of harvested lymph nodes was 31 (range=16-82). The median number of metastatic lymph nodes was 7.7 (range $=1$ 52 ). The cutoff value for the LNR was set at 0.23 based on the 3 - and 5-year OS rates and according to the results of previous studies (Table I). The study population was classified into the low-LNR $(\mathrm{LNR}<0.23 ; \mathrm{n}=54)$ and high-LNR $(\mathrm{LNR} \geq 0.23$; $n=32$ ) groups. There were no significant differences in the background characteristics of the two groups, including the median age, median operation time, median blood loss, and median number of harvested lymph nodes.

Survival analysis and patterns of recurrence. Clinicopathological factors were categorized and analyzed to evaluate their prognostic significance (Table II). T factor and LNR were identified as significant prognostic factors by the univariate analysis of factors associated with OS. The LNR was therefore included in the final multivariate analysis model. The OS rate at 3 and 5 years after surgery was $57.6 \%$ and $57.6 \%$, respectively, in the low-LNR group and $33.0 \%$ and $0 \%$ in high-LNR group $(p<0.001)$. The LNR was a significant prognostic factor by the univariate analysis of factors associated with RFS. Thus, RFS was therefore included as a significant prognostic factor in the final multivariate analysis model (Table III). The RFS rate at 3 and 5 years after surgery was $45.9 \%$ and $43.6 \%$, respectively, in the low-LNR group, and $25.2 \%$ and $0 \%$ in the high-LNR group $(p=0.002)$. The OS and RFS curves are shown in Figure 1 and Figure 2, respectively. Regarding the site of first relapse (Table IV), the incidence rates of peritoneal and lymph node recurrence in the high-LNR group were significantly higher in comparison to the low-LNR group.

Subgroup analysis according to pathological $N$ stage. The clinical impact of the LNR was evaluated in each pathological (p) N stage. In patients with pN1 (1-2 metastatic lymph nodes), the OS rate at 3 and 5 years after surgery was $58.5 \%$ and $58.5 \%$, respectively, in the low-LNR group; there were no patients with $\mathrm{pN} 1$ disease in the high-LNR group. In the patients with pN2 (3-6 metastatic lymph nodes), the OS rate at 3 and 5 years after surgery was $67.3 \%$ and $67.3 \%$, respectively, in the low-LNR group and $75.0 \%$ and $0.0 \%$ in high-LNR group. In the patients with $\mathrm{pN} 3$ ( $\geq 8$ metastatic 
Table III. Uni- and Multi-variate Cox proportional hazards analysis of clinicopathological factors for recurrence free survival.

\begin{tabular}{|c|c|c|c|c|c|c|c|}
\hline \multirow[b]{2}{*}{ Factors } & \multirow[b]{2}{*}{ No } & \multicolumn{3}{|c|}{ Univariate analysis } & \multicolumn{3}{|c|}{ Multivariate analysis } \\
\hline & & OR & $95 \% \mathrm{CI}$ & $p$-Value & OR & $95 \% \mathrm{CI}$ & $p$-Value \\
\hline Age (years) & & & & 0.522 & & & \\
\hline$<70$ & 41 & 1.000 & & & & & \\
\hline$\geq 70$ & 45 & 1.195 & $0.692-2.062$ & & & & \\
\hline Gender & & & & 0.828 & & & \\
\hline Woman & 30 & 1.000 & & & & & \\
\hline Man & 56 & 1.067 & $0.597-1.905$ & & & & \\
\hline Pathological type & & & & 0.688 & & & \\
\hline Intestinal & 44 & 1.000 & & & & & \\
\hline Diffuse & 42 & 1.118 & $0.648-1.931$ & & & & \\
\hline $\mathrm{T}$ status & & & & 0.006 & & & 0.040 \\
\hline $\mathrm{T} 1$ to $\mathrm{T} 2$ & 23 & 1.000 & & & 1.000 & & \\
\hline $\mathrm{T} 3$ to $\mathrm{T} 4$ & 63 & 2.868 & $1.345-6.115$ & & 2.297 & $1.038-5.085$ & \\
\hline Lymph node ratio & & & & 0.002 & & & 0.037 \\
\hline$<0.23$ & 54 & 1.000 & & & 1.000 & & \\
\hline$\geq 0.23$ & 32 & 2.350 & $1.354-4.081$ & & 1.853 & $1.039-3.302$ & \\
\hline Lymphatic invasion & & & & 0.595 & & & \\
\hline Negative & 10 & 1.000 & & & & & \\
\hline Positive & 76 & 1.260 & $0.537-2.953$ & & & & \\
\hline Vascular invasion & & & & 0.273 & & & \\
\hline Negative & 17 & 1.000 & & & & & \\
\hline Positive & 69 & 1.495 & $0.728-3.069$ & & & & \\
\hline Postoperative complications & & & & 0.101 & & & \\
\hline No & 48 & 1.000 & & & & & \\
\hline Yes & 38 & 1.583 & $0.915-2.738$ & & & & \\
\hline
\end{tabular}

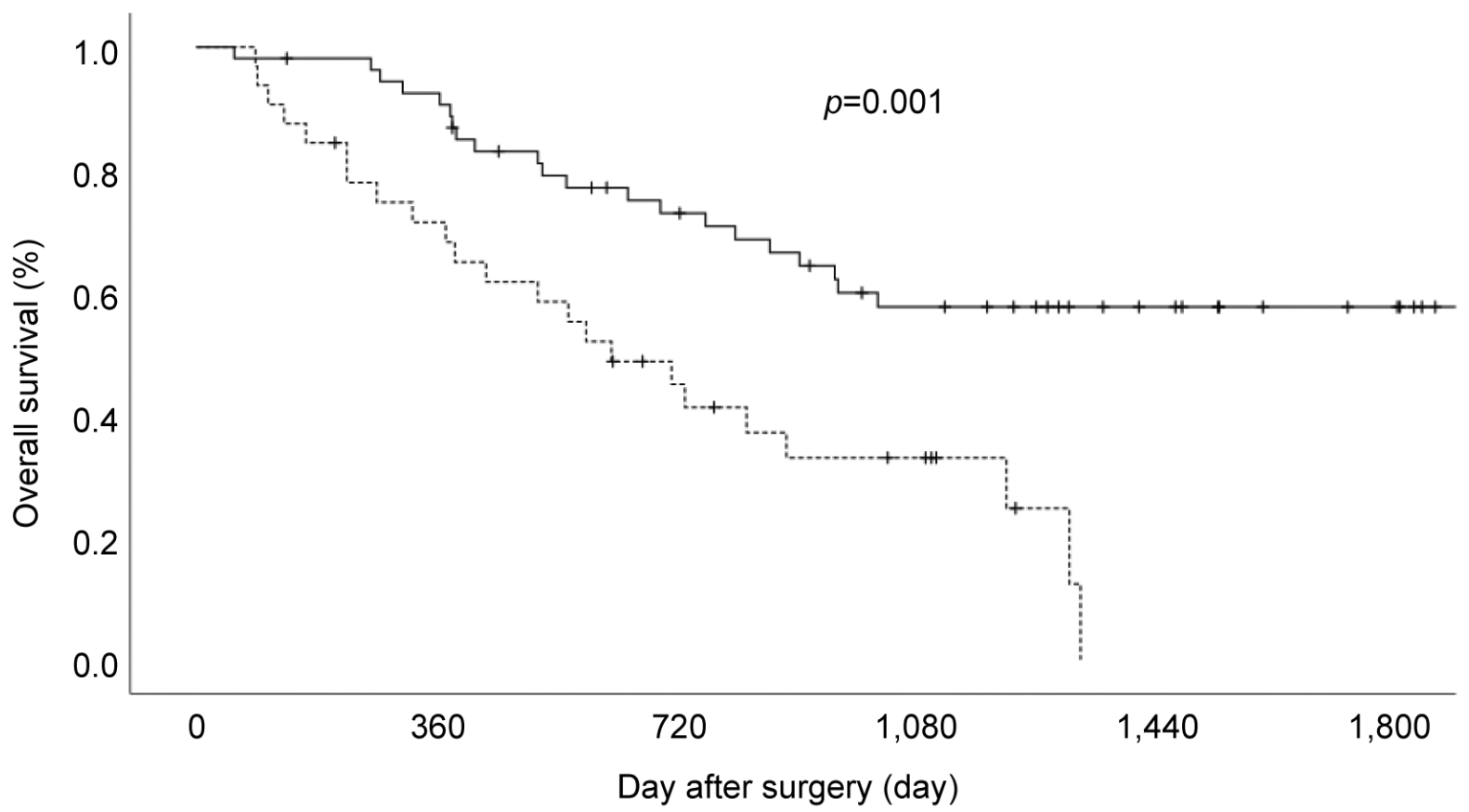

Figure 1. Overall survival in patients with lymph node ratios of $>0.23$ and $\leq 0.23$. 


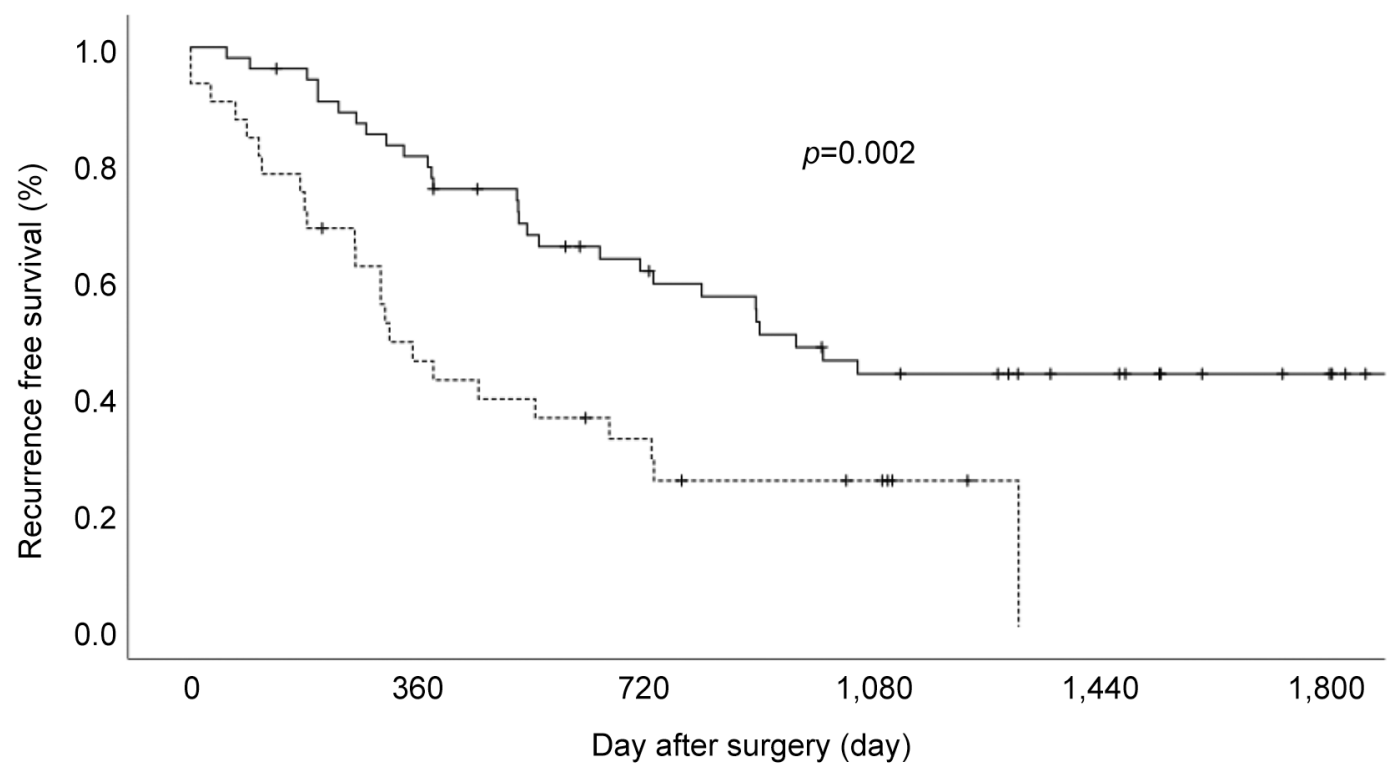

Figure 2. Recurrence-free survival in patients with lymph node ratios $>0.23$ and $\leq 0.23$.

Table IV. Patterns of recurrence between the patients with lymph node ratio $<0.23$ and those with count score $\geq 0.23$.

\begin{tabular}{|c|c|c|c|c|c|c|c|}
\hline \multirow[b]{2}{*}{ Recurrence site } & \multicolumn{2}{|c|}{$\begin{array}{l}\text { All cases } \\
(\mathrm{n}=86)\end{array}$} & \multicolumn{2}{|c|}{$\begin{array}{l}<0.23 \\
(\mathrm{n}=54)\end{array}$} & \multicolumn{2}{|c|}{$\begin{array}{l}\geq 0.23 \\
(\mathrm{n}=32)\end{array}$} & \multirow[b]{2}{*}{$p$-Value } \\
\hline & Number & $\%$ & Number & $\%$ & Number & $\%$ & \\
\hline Peritoneal & 23 & 26.7 & 9 & 16.7 & 14 & 43.8 & 0.006 \\
\hline Lymph node & 13 & 15.1 & 4 & 7.4 & 9 & 28.1 & 0.010 \\
\hline Hematological & 18 & 20.9 & 8 & 14.8 & 10 & 31.3 & 0.070 \\
\hline Local site & 4 & 4.7 & 2 & 3.7 & 2 & 6.3 & 0.633 \\
\hline
\end{tabular}

lymph nodes), the OS rate at 3 and 5 years after surgery was $50.0 \%$ and $25.0 \%$, respectively, in the low-LNR group, and $25.0 \%$ and $0.0 \%$ in high-LNR group.

\section{Discussion}

The present study aimed to investigate whether the LNR is a prognostic factor for lymph node metastasis-positive gastric cancer patients who receive curative treatment. The major finding of the present study was that the LNR was a prognostic factor for these patients. Furthermore, the clinical value of the LNR as a prognostic factor was higher in patients with $\mathrm{pN} 3$ disease in comparison to those with $\mathrm{pN} 1$ or pN2 disease. The present study therefore suggested that that the LNRs should be considered in the development of treatment strategies for gastric cancer, especially for patients with a more advanced $\mathrm{N}$ factor.

The hazard ratio (HR) of the LNR was 2.849, [95\% confidence interval $(\mathrm{CI})=1.559-5.207]$ for $\mathrm{OS}$ and 2.350
(95\% CI=1.354-4.081) for RFS. In previous studies, similar findings were reported in patients with gastrointestinal malignancies, including gastric cancer. Nakamura et al. evaluated the clinical influence of LNR in 973 gastric cancer patients with lymph node metastasis (21). They set the cutoff value of the LNR at 0.737 and classified 583 patients into lowLNR group and 390 patients into high-LNR group. They found that a high LNR was associated with significantly shorter disease-free survival (DFS) and disease-specific survival (DSS) in comparison to a low LNR group ( $\mathrm{HR}=3.64$ for DFS and $\mathrm{HR}=4.15$ for DDS). Kim et al. evaluated the influence of the metastatic lymph node ratio in data from the adjuvant chemoradiotherapy in stomach tumor (ARTIST) trial (22). In their retrospective study, they analyzed 458 patients from the ARTIST trial. The patients were divided into 4 groups according to the lymph node ratio $(0 \%, 1-9 \%, 10-25 \%$, and $\geq 25 \%$ ). The HR was 1.000 for a lymph node ratio of $0 \%, 1.061$ for a lymph node ratio of 1-9\%, 1.202 for a lymph node ratio of $10-25 \%$, and 3.571 for a lymph node ratio of $\geq 25 \%$. Thus, 
the LNR might have some clinical impact in patients with gastric cancer and lymph node metastasis who receive curative treatment. On the other hand, in the present study, the LNR showed higher clinical value as a prognostic factor in patients with $\mathrm{pN} 3$ disease in comparison to those with $\mathrm{pN} 1$ or $\mathrm{pN} 2$ disease. In the subgroup analysis, there were statistically significant survival differences in the survival of the high-LNR and low-LNR groups in patients with pN3 disease, but not in patients with $\mathrm{pN} 1$ or $\mathrm{pN} 2$ disease. The prognostic value of the LNR may therefore be limited to patients with an advanced tumor stage. Similar results were observed in previous studies. Hung et al. evaluated the clinical impact of the LNR in 139 gastric cancer patients with $>15$ metastatic regional lymph nodes (23). In their study, the cutoff value of the LNR was set at 0.80 . They showed that the HR of a high LNR for OS was 1.61 (1.01-2.56) in comparison to a low LNR. In addition, Wu et al. evaluated the prognostic value of the metastatic lymph node ratio in 745 gastric cancer patients who received curative surgery and in whom at least 15 lymph nodes were examined (24). They demonstrated that the LNR only had prognostic value in patients with stage III gastric cancer $(p<0.001)$; it was not a significant prognostic factor in gastric cancer patients with stage I ( $p=0.877)$ or II $(p=0.169)$ disease. Considering the present study and the previous studies, the clinical value of the LNR as a prognostic factor in gastric cancer patients may be limited to those with an aggressive tumor stage. This issue should be investigated in further studies.

To utilize the LNR as prognostic factor in gastric cancer treatment, it is necessary to set an optimal cutoff value. In the present study, we used a cutoff value of 0.23 based on the 3and 5-year survival rates. Previous studies have used cutoff values of $0.25-0.80$ (21-24). The differences in the cutoff values are explained by differences in patient background factors and in the methods of evaluation. First, with regard to patient background, the present study and the studies of Nakamura et $a l$. and Hung et al. only evaluated patients with lymph node metastasis, while the study by Deng et al. evaluated patients with and without lymph node metastasis (21-24). Second, numbers of harvested lymph nodes and metastasis-positive lymph nodes were different. In our study, the median number of harvested lymph nodes was 31 (range=21-82) and the median number of metastasis-positive lymph nodes was 7.7 (range=152). In contrast, Deng et al. reported that the mean number of metastasis-positive lymph nodes was $4.84 \pm 2.19$ and the mean number of metastasis-negative lymph nodes was $13.01 \pm 9.65$ (24). Hwang et al. reported that the median number of harvested lymph nodes was 44 (range=33-55). In addition, the median number of metastasis-positive lymph nodes was 4 (range=1-7) in patients with lymph node metastasis (25). Moreover, Hung et al. reported that the median number of harvested lymph nodes was 44 (range $=17-135$ ) and the median number of metastatic lymph nodes was 22 (range=16-67) (22). The differences in the numbers of harvested lymph nodes and metastatic nodes might have affected the LNR. Third, the methods of evaluation were different. In the present study, we set the cutoff value according to the 3- and 5-year survival rates. On the other hand, other studies set their cutoff value according to a receiver operating characteristic curve analysis (21-24). Taken together, further studies are required to determine the optimal cutoff value for the LNR.

In conclusion, the LNR was a prognostic factor for patients with gastric cancer and lymph node metastasis who received curative treatment. The clinical value of the LNR as a prognostic factor was higher in patients with a more advanced $\mathrm{N}$ factor. Thus, the present study suggested that the LNR should be considered in the development of treatment strategies for gastric cancer, especially for patients with a more advanced $\mathrm{N}$ factor.

\section{Conflicts of Interest}

The Authors declare no conflicts of interest in association with the present study.

\section{Authors' Contributions}

TA and MN made substantial contributions to the concept and design. TA, MN, KS, SN, HS, KK, TY, IH, HW, MN, HT, TO, NY, TO and YR made substantial contributions to the acquisition of data and the analysis and interpretation of data. TA, HW, MN, HT, TO, NY and YR were involved in drafting the article or revising it critically for important intellectual content. All Authors gave their final approval of the version to be published.

\section{Acknowledgements}

This work was supported by JSPS KAKENHI Grant Number $21 \mathrm{~K} 08688$.

\section{References}

1 Ferlay J, Colombet M, Soerjomataram I, Mathers C, Parkin DM, Piñeros M, Znaor A and Bray F: Estimating the global cancer incidence and mortality in 2018: GLOBOCAN sources and methods. Int J Cancer 144(8): 1941-1953, 2019. PMID: 30350310. DOI: 10.1002/ijc.31937

2 Bray F, Ferlay J, Soerjomataram I, Siegel RL, Torre LA and Jemal A: Global cancer statistics 2018: GLOBOCAN estimates of incidence and mortality worldwide for 36 cancers in 185 countries. CA Cancer J Clin 68(6): 394-424, 2018. PMID: 30207593. DOI: $10.3322 /$ caac. 21492

3 Ferlay J, Soerjomataram I, Dikshit R, Eser S, Mathers C, Rebelo M, Parkin DM, Forman D and Bray F: Cancer incidence and mortality worldwide: sources, methods and major patterns in GLOBOCAN 2012. Int J Cancer 136(5): E359-E386, 2015. PMID: 25220842. DOI: 10.1002/ijc.29210

4 Noguchi M and Miyazaki I: Prognostic significance and surgical management of lymph node metastasis in gastric cancer. Br J Surg 83(2): 156-161, 1996. PMID: 8689153. 
5 Huang JY, Xu YY, Li M, Sun Z, Zhu Z, Song YX, Miao ZF, Wu $\mathrm{JH}$ and $\mathrm{Xu} \mathrm{HM}$ : The prognostic impact of occult lymph node metastasis in node-negative gastric cancer: a systematic review and meta-analysis. Ann Surg Oncol 20(12): 3927-3934, 2013. PMID: 23892524. DOI: 10.1245/s10434-013-3021-7

6 Deng JY and Liang H: Clinical significance of lymph node metastasis in gastric cancer. World J Gastroenterol 20(14): 3967 3975, 2014. PMID: 24744586. DOI: 10.3748/wjg.v20.i14.3967

7 Edge SB and Compton CC: The American Joint Committee on Cancer: the $7^{\text {th }}$ edition of the AJCC cancer staging manual and the future of TNM. Ann Surg Oncol 17(6): 1471-1474, 2010. PMID: 20180029. DOI: 10.1245/s10434-010-0985-4

8 Japanese Gastric Cancer Association: Japanese classification of gastric carcinoma: 3rd English edition. Gastric Cancer 14(2): 101112, 2011. PMID: 21573743. DOI: 10.1007/s10120-011-0041-5

9 Yukawa N, Aoyama T, Tamagawa H, Tamagawa A, Atsumi Y, Kawahara S, Maezawa Y, Kano K, Murakawa M, Kazama K, Numata M, Oshima T, Masuda M and Rino Y: The lymph node ratio is an independent prognostic factor in esophageal cancer patients who receive curative surgery. In Vivo 34(4): 2087-2093, 2020. PMID: 32606187. DOI: 10.21873/invivo.12012

10 Ceelen W, Van Nieuwenhove Y and Pattyn P: Prognostic value of the lymph node ratio in stage III colorectal cancer: a systematic review. Ann Surg Oncol 17(11): 2847-2855, 2010. PMID: 20559741. DOI: 10.1245/s10434-010-1158-1

11 Aoyama T, Yamamoto N, Kamiya M, Murakawa M, Tamagawa H, Sawazaki S, Numata M, Shiozawa M, Kobayashi S, Ueno M, Morimoto M, Yukawa N, Oshima T, Yoshikawa T, Rino Y, Masuda $\mathrm{M}$ and Morinaga S: The lymph node ratio is an independent prognostic factor in pancreatic cancer patients who receive curative resection followed by adjuvant chemotherapy. Anticancer Res 38(8): 4877-4882, 2018. PMID: 30061263. DOI:10.21873/anticanres.12801

12 Aoyama T, Atsumi Y, Kawahara S, Tamagawa H, Tamagawa A, Maezawa Y, Kano K, Murakawa M, Kazama K, Numata M, Oshima T, Yukawa N, Masuda M and Rino Y: The number of harvested LNs is an independent prognostic factor in lymph node metastasis-negative patients who received curative esophagectomy. In Vivo 34(4): 2021-2027, 2020. PMID: 32606176. DOI: 10.21873 /invivo.12001

13 Kim Y, Squires MH, Poultsides GA, Fields RC, Weber SM, Votanopoulos KI, Kooby DA, Worhunsky DJ, Jin LX, Hawkins WG, Acher AW, Cho CS, Saunders N, Levine EA, Schmidt CR, Maithel SK and Pawlik TM: Impact of lymph node ratio in selecting patients with resected gastric cancer for adjuvant therapy. Surgery 162(2): 285-294, 2017. PMID: 28578142. DOI: 10.1016/j.surg.2017.03.023

14 Ema A, Yamashita K, Sakuramoto S, Wang G, Mieno H, Nemoto M, Shibata T, Katada N, Kikuchi S and Watanabe M: Lymph node ratio is a critical prognostic predictor in gastric cancer treated with S-1 chemotherapy. Gastric Cancer 17(1): 67-75, 2014. PMID: 23801337. DOI: 10.1007/s10120-013-0253-y

15 Melis M, Masi A, Pinna A, Cohen S, Hatzaras I, Berman R, Pachter LH and Newman E: Does lymph node ratio affect prognosis in gastroesophageal cancer? Am J Surg 210(3): 443-450, 2015. PMID: 26003203. DOI: 10.1016/j.amjsurg.2014.12.042

16 Japanese Gastric Cancer Association: Japanese gastric cancer treatment guidelines 2018 ( $5^{\text {th }}$ edition). Gastric Cancer 24(1): 121, 2021. PMID: 32060757. DOI: 10.1007/s10120-020-01042-y

17 Sakuramoto S, Sasako M, Yamaguchi T, Kinoshita T, Fujii M, Nashimoto A, Furukawa H, Nakajima T, Ohashi Y, Imamura H,
Higashino M, Yamamura Y, Kurita A, Arai K and ACTS-GC Group: Adjuvant chemotherapy for gastric cancer with S-1, an oral fluoropyrimidine. N Engl J Med 357(18): 1810-1820, 2007. PMID: 17978289. DOI: 10.1056/NEJMoa072252

18 Bang YJ, Kim YW, Yang HK, Chung HC, Park YK, Lee KH, Lee KW, Kim YH, Noh SI, Cho JY, Mok YJ, Kim YH, Ji J, Yeh TS, Button P, Sirzén F, Noh SH and CLASSIC trial investigators: Adjuvant capecitabine and oxaliplatin for gastric cancer after D2 gastrectomy (CLASSIC): a phase 3 open-label, randomised controlled trial. Lancet 379(9813): 315-321, 2012. PMID: 22226517. DOI: 10.1016/S0140-6736(11)61873-4

19 Yoshida K, Kodera Y, Kochi M, Ichikawa W, Kakeji Y, Sano T, Nagao N, Takahashi M, Takagane A, Watanabe T, Kaji M, Okitsu H, Nomura T, Matsui T, Yoshikawa T, Matsuyama J, Yamada $\mathrm{M}$, Ito $\mathrm{S}$, Takeuchi $\mathrm{M}$ and Fujii $\mathrm{M}$ : Addition of docetaxel to oral fluoropyrimidine improves efficacy in patients with stage III gastric cancer: Interim analysis of JACCRO GC07, a randomized controlled trial. J Clin Oncol 37(15): 12961304, 2019. PMID: 30925125. DOI: 10.1200/JCO.18.01138

20 Aoyama T, Fujikawa H, Cho H, Ogata T, Shirai J, Hayashi T, Rino Y, Masuda M, Oba MS, Morita S and Yoshikawa T: A methylene blue-assisted technique for harvesting lymph nodes after radical surgery for gastric cancer: a prospective, randomized, controlled study. Am J Surg Pathol 39(2): 266-273, 2015. PMID: 25356528. DOI: 10.1097/PAS.0000000000000336

21 Nakamura S, Kanda M, Ito S, Mochizuki Y, Teramoto H, Ishigure K, Murai T, Asada T, Ishiyama A, Matsushita H, Tanaka C, Kobayashi D, Fujiwara M, Murotani K and Kodera Y: Accurate risk stratification of patients with node-positive gastric cancer by lymph node ratio. World J Surg 44(12): 4184-4192, 2020. PMID: 32892273. DOI: 10.1007/s00268-020-05739-0

22 Kim Y, Park SH, Kim KM, Choi MG, Lee JH, Sohn TS, Bae JM, Kim S, Lee SJ, Kim ST, Lee J, Park JO, Park YS, Lim HY and Kang WK: The influence of metastatic lymph node ratio on the treatment outcomes in the adjuvant chemoradiotherapy in stomach tumors (ARTIST) trial: a phase III trial. J Gastric Cancer 16(2): 105-110, 2016. PMID: 27433396. DOI: 10.5230/ jgc.2016.16.2.105

23 Hung YS, Chang SC, Liu KH, Hung CY, Kuo YC, Tsai CY, Hsu JT, Yeh TS, Chen JS and Chou WC: A prognostic model based on lymph node metastatic ratio for predicting survival outcome in gastric cancer patients with N3b subclassification. Asian J Surg 42(1): 85-92, 2019. PMID: 29248301. DOI: 10.1016/ j.asjsur.2017.10.001

24 Wu XJ, Miao RL, Li ZY, Bu ZD, Zhang LH, Wu AW, Zong XL, Li SX, Shan F, Ji X, Ren H and Ji JF: Prognostic value of metastatic lymph node ratio as an additional tool to the TNM stage system in gastric cancer. Eur J Surg Oncol 41(7): 927-933, 2015. PMID: 25913059. DOI: 10.1016/j.ejso.2015.03.225

25 Hwang JE, Kim H, Shim HJ, Bae WK, Hwang EC, Jeong O, Ryu SY, Park YK, Cho SH and Chung IJ: Lymph-node ratio is an important clinical determinant for selecting the appropriate adjuvant chemotherapy regimen for curative D2-resected gastric cancer. J Cancer Res Clin Oncol 145(8): 2157-2166, 2019. PMID: 31273512. DOI: 10.1007/s00432-019-02963-7

Received December 26, 2021

Revised January 12, 2022

Accepted January 13, 2022 